\title{
4. Ever-changing Big Science and Research Infrastructures: Evolving European Union policy
}

\section{Inga Ulnicane}

\section{INTRODUCTION}

Big Science and Research Infrastructures (RIs) keep changing and evolving along with major organizational, technological and political changes that affect science. A recent comprehensive analysis of the transformation of Big Science of the Cold War era to a new context showed that the "old Big Science" was characterized by large teams and long-term experiments, accelerators for particle collisions and reactors for nuclear research and had a clear military connection (Hallonsten 2016). In contrast, the key features of the "transformed Big Science" include large support organizations, accelerators and reactors for neutron scattering, synchrotron radiation and free electron laser; it focuses on innovation-based (regional economic) growth, sustainability and addressing grand challenges.

This chapter aims to study ongoing changes of Big Science and RIs by looking at evolving European Union (EU) policy. Since the year 2000, important changes have taken place in EU policymaking that affect Big Science and RIs. In particular, this chapter will look at the emergence of EU policy for RIs in a differentiated integration mode, EU support for politically motivated large-scale research projects and e-infrastructures, as well as the development of RI policy within the European Research Area (ERA) initiative. To illustrate these EU policy changes, an example of an EU-funded large-scale research initiative, the Human Brain Project (HBP), currently developing, will be used. The main research method in this chapter will be document analysis. Study of public discourse and official announcements - as one of the often used qualitative methods to study Big Science and RIs (see Rüffin, ch 2 in this volume) - will be used to analyze a broad range of documents from EU institutions and expert groups. 
Thus, this chapter aims to contribute to this volume by delving into EU-level policy changes affecting Big Science and RIs in Europe. This way, it complements other chapters focusing on policy, such as Bolliger and Griffiths (ch 5 in this volume) analyzing RI roadmaps, and Moskovko (ch 6 in this volume) on the European Research Infrastructure Consortium (ERIC) framework. While there are many factors affecting Big Science and RIs, policy is definitely one of them as it sets out boundary conditions (regulation, coordination mechanisms, funding, etc.) for establishing and sustaining Big Science and RI projects. Due to important changes taking place in EU research policy since 2000, this is an important topic for understanding current contexts in which Big Science and RIs operate in Europe.

This chapter proceeds as follows: first, concepts of Big Science, RIs, international research collaboration and science diplomacy are discussed. Second, different models of European integration - intergovernmental, uniform and differentiated - are discussed to shed light on the evolution of EU policy concerning Big Science and RIs in a differentiated integration mode. Third, changes in EU research policy related to large-scale politically motivated projects, e-infrastructures and the ERA are outlined. Fourth, the example of the HBP is used to illustrate some trends in EU policy changes in this area. Finally, conclusions and questions for future research are presented.

\section{CONCEPTUAL FRAMEWORK: HOW TO UNDERSTAND BIG SCIENCE AND RESEARCH INFRASTRUCTURES}

This chapter draws on the related concepts of Big Science, RIs, international research collaboration and science diplomacy, and applies them to relevant developments in Europe. While the partly overlapping concepts of Big Science and RIs have been understood and used by researchers and policymakers in many different ways, this chapter follows the common approach outlined for this book by Cramer et al (ch 1 in this volume).

Big Science is understood here according to Hallonsten (2016: 17) as "science made big in three dimensions: big organizations, big machines, and big politics". Big organizations mean the organization of large scientific projects in an industrial manner, or hierarchical structure of large teams formed around a large and costly scientific instrument (Cramer et al, ch 1 in this volume). Big machines refer to the size of scientific instruments, while big politics point to substantial political support needed for large-scale research endeavors.

Many Big Science facilities and projects are also RIs, which in this book is understood as a specific policy concept widely used in the EU (Cramer et al, ch 1 in this volume). The European Commission defines RIs as "facil- 
ities, resources and services used by the science community to conduct research and foster innovation". RIs "include: major scientific equipment, resources such as collections, archives or scientific data, e-infrastructures such as data and computing systems, and communication networks" that "can be single-sited (a single resource at a single location), distributed (a network of distributed resources), or virtual (the service is provided electronically)". The Commission categorizes European RIs in three organizational groups: firstly, intergovernmental that are established by the member states; secondly, new pan-European that are listed in the European Strategy Forum on Research Infrastructures (ESFRI) roadmap, including ERICs; and thirdly, national RIs of European interest that receive European support (European Commission 2019a).

After analyzing the 60 RIs identified as important for Europe by the EU institutions, Hallonsten (2020) concludes that the concept of RIs is ill-defined, and that the current policy hype around RIs in Europe "is not matched by any substance on the side of what qualifies as a RI and not, and why". According to him, "Research Infrastructures (RIs) are resources that enable scientific research or development work. They can be open-ended in their use, and they can take a variety of technological shapes and forms including instruments and tools for discovery and experimentation, repositories of data and materials, and vessels for exploration". He highlights the political origins and political usefulness of this term in the context of a recent increase in policy attention that the concept of RIs has received at the EU level.

Many Big Science initiatives and large-scale RIs are international because their scale requires pooling of scientific and material resources from several countries. Such RIs are examples of international research collaborations (Ulnicane 2015a). Scientific research has for centuries been characterized by active (international) collaboration, exchange of knowledge and mobility across borders (Crawford et al 1993). Today, research practices are highly internationalized (Nedeva 2013) and international research collaboration as measured by co-authorships is increasing (Wagner et al 2015) due to factors such as increasing scientific specialization and complexity of research, the need to address cross-border problems and escalating costs of research equipment.

To understand RIs as a specific kind of international research collaboration, it is useful to draw on a distinction made by Wagner (2008) between "top-down" and "bottom-up" international research collaborations. Many scientific collaborations are "bottom up", namely driven and organized by individual researchers. They are typically small-scale initiatives to combine complementary expertise and capabilities to address research questions of mutual interest and solve scientific problems. In contrast, Big Science and RIs typically require large-scale national and international funding. According to 
Wagner (2008: 26), “[g]overnment officials typically plan such facilities in discussion with scientists and sink significant investment in their construction before any research ever takes place. The organization of these activities can therefore be considered "top-down". Thus, in contrast to small-scale self-organizing international research collaborations among scientists, Big Science and RIs that are international collaborations are more dependent on political and governmental support and steering.

As new Big Science initiatives are launched, and this mode of collaboration and organization expands to further scientific disciplines, debate over its relative merits continues. Among the benefits of Big Science are typically mentioned opportunities to bring together diverse types of expertise across disciplinary, organizational and national boundaries to address complex problems, while bureaucratization and politicization are often highlighted as negative consequences of Big Science (e.g. Vermeulen et al 2010).

Large-scale international scientific collaborations behind Big Science and RI initiatives today are often described by another popular term of science diplomacy. A broad understanding of the concept of science diplomacy typically sees it as an intersection between science and technology policy and foreign affairs (Royal Society 2010). A popular definition, originating with the Royal Society (2010: 15), distinguishes between the three dimensions of science diplomacy. First, "science in diplomacy" focuses on informing foreign policy objectives with scientific advice. Second, "diplomacy for science" facilitates international scientific cooperation. Third, "science for diplomacy" uses science cooperation to improve international relations. The second dimension, diplomacy for science, is the most relevant for understanding political processes and diplomatic efforts behind establishing and maintaining Big Science and RI projects. Some Big Science and RI initiatives can also be examples of the third dimension, science for diplomacy, where science cooperation is seen as a tool to improve diplomatic relations.

The following analysis of changing organization, instrumentation and politics of Big Science and RIs will draw on the above-mentioned concepts.

\section{MODES OF EUROPEAN INTEGRATION AND CHANGING BIG SCIENCE AND RESEARCH INFRASTRUCTURES}

As the introductory chapter to this book reminds us, the history of Big Science and RIs is closely connected to the history of European integration. European integration processes, institutions and policies have changed over time and "the ever-changing Union" (Egenhofer et al 2011) has also had an impact on Big Science and RIs. This section will look at different modes of European integration - intergovernmental, uniform and differentiated - and their relevance 
for Big Science and RIs. The intergovernmental mode of integration refers to collaboration among governments outside the EU framework, uniform mode of integration refers to policies and institutions that applies to all EU member states, while differentiated integration includes EU policies in which some EU member states do not participate while some non-members may participate. History and policies of Big Science and RIs in Europe include elements of all these three modes: intergovernmental, uniform and differentiated. Looking at Big Science and RIs from the perspective of different modes of European integration helps to connect developments of Big Science and RIs with long-term processes in European integration.

\subsection{From Intergovernmental Cooperation to European Union Policy}

Major Big Science initiatives started in the 1950s as intergovernmental cooperation among a number of national governments. At that time uniform EU integration in the field of research was almost non-existent. These intergovernmental initiatives included large-scale research facilities such as the European Organization of Nuclear Research (CERN, established in 1954), the European Southern Observatory (ESO, established in 1962), the European Space Research Organisation (ESRO) and European Launcher Development Organization (ELDO) (1964), the Institut Laue-Langevin (ILL) (1967), the European Molecular Biology Laboratory (EMBL, established in 1974), the European Space Agency (ESA, established in 1975) and the European Synchrotron Radiation Facility (ESRF) (1988) (see Cramer, ch 3 in this volume; D'Ippolito and Rüling, ch 11 in this volume).

These intergovernmental initiatives were "built on ad hoc solutions rather than a coherent political framework and common regulatory standards" (Hallonsten 2014: 31). Diverse organizational formats have been used: while CERN, ESA, ESO and EMBL are international organizations operating according to international rules with permanent international staff, ESRF and ILL are private entities operating as companies according to the legislation of the host country and with national labor law constraints (Papon 2009: 36).

Such lack of coherence and reliance on ad hoc solutions for each new intergovernmental initiative has both advantages and disadvantages. Advantages are flexibility, avoidance of bureaucracy and institutional inertia and allowing each initiative to meet the demands of its specific scientific community at a specific time (Hallonsten 2014: 35; Papon 2004), while disadvantages include lack of transparency, an in-built uncertainty, unpredictability, the need to reinvent legal arrangements and organizational structures for each project and, thus, delays in their realization (Hallonsten 2015). Typically, critical issues involved in setting up such intergovernmental initiatives are site selection, fair return and in-kind contributions (Hallonsten 2012), which often 
have to be resolved through complex political compromises. Hallonsten (2014: 35) argues that each country joining such initiatives undertakes a multitrack cost-benefit analysis, weighing possible economic, political, diplomatic and reputational gains and losses. According to him, "most countries realize that collaboration is necessary to achieve goals beyond the reach of any one of them, but strong traditions of sovereignty create tension between self-interest and common good, for every partaking country, in every collaboration" (Hallonsten 2014: 35). Krige $(2002,2003)$ argues that European intergovernmental science organizations aim at both promoting the national interests of the participating countries and contributing to the European integration process, and that they are not undertaken at the expense of self-interest but rather allow countries "the pursuit of one's interests by other means" (Krige 2003: 900).

In parallel with intergovernmental cooperation among member states, EU integration gradually expanded to new policy areas, including research. Major milestones in the development of EU research policy include the establishment of multi-annual EU Framework Programmes (FP) for funding research, in 1984, and the launch of the ERA initiative in 2000. According to the Lisbon Treaty that came into force in 2009, research policy is a shared competence between the EU and the member states, which implies that in this policy area both the EU and its member states are able to legislate and adopt legally binding acts. Major EU policy developments for Big Science and RIs include the establishment of ESFRI in 2002 (Bolliger and Griffiths, ch 5 in this volume) and the approval of the ERIC legal framework in 2009 (Moskovko, ch 6 in this volume; Moskovko et al 2019).

The ERIC framework was established by a Council of the EU regulation in 2009 (European Commission 2019b) to facilitate the joint establishment and operation of research infrastructures of European interest among several member states and associated countries. Additionally, membership of ERICs can include third countries and intergovernmental organizations. The minimum requirement for setting up an ERIC is to have at least one EU member state and two other countries that are either EU member states or associated countries. Member states and associated countries must jointly hold the majority of voting rights in the assembly of members. The headquarters of a consortium should be located either in a member state or in an associated country. The ERIC framework has been used both for establishing new infrastructures and as a new organizational framework for existing research initiatives (Moskovko, ch 6 in this volume).

Thus, the ERIC framework builds on experiences of intergovernmental initiatives and offers EU solutions to some of the difficulties encountered (e.g. lengthy negotiations, reinventing new rules for each facility ad hoc) to ensure a faster and more transparent process of establishing joint research facilities 
(European Commission 2014b). However, while the ERIC framework can solve some of the problems it can also create new ones. Some important practical advantages and challenges of this framework were illustrated by the case of the European Social Survey becoming an ERIC in 2013. For the Survey, becoming an ERIC allowed it to tackle the challenge of long-term survival and funding but also led to the decline in the number of participating countries and thus to less comprehensive coverage because a number of countries decided not to join the ERIC or to join only as observers (Duclos Lindstrom and Kropp 2017).

\subsection{Differentiated Integration}

The ERIC model, that brings together only some EU member states and might include countries from outside the EU, is a case of the differentiated (rather than uniform) mode of European integration. Moreover, it is not the only case of differentiated integration in research policy. The core instrument of the EU research and innovation policy, namely the FP, is also a case of differentiated integration because in addition to the EU member states it also includes a considerable number of associated countries (Fumasoli et al 2015; Langfeldt et al 2012; Lavenex 2009). Sixteen associated countries are participating fully or partially in the most recent FP called Horizon 2020 and are making financial contributions to it (European Commission 2019c). Considering the significance of differentiated integration for RIs, and more generally for EU research policy (Chou and Ulnicane 2015), it is worthwhile to take a closer look at differentiated integration, what is driving it and why initiatives for RIs and research policy develop as cases of differentiated rather than uniform integration.

Differentiated integration characterizes "all those policies, in which the territorial extension of European Union (EU) membership and EU rule validity are incongruent" (Holzinger and Schimmelfennig 2012: 292). Well-known examples of differentiated integration in other policy areas include the Economic and Monetary Union where several EU member states do not participate, and the Schengen zone where some EU members do not participate but some non-members participate (Holzinger and Schimmelfennig 2012). Such initiatives, also known as "multi-speed Europe", "flexible integration", "variable geometry", "Europe à la carte" and "graded membership" (Holzinger and Schimmelfennig 2012; Kölliker 2001; Leruth and Lord 2015; Schimmelfennig 2016), are seen as "an essential and, most likely, enduring characteristic of the EU" (Schimmelfennig et al 2015: 765).

While historically examples of differentiated integration might have been seen as temporary phenomena that eventually will lead to full EU integration, data suggest that differentiation has significantly increased over time 
(Schimmelfennig et al 2015: 770). In European studies today, differentiated integration is recognized as "a permanent, organizational principle of the Union, grounded in a need to manage divisions and disagreements that just do not go away" (Leruth and Lord 2015: 758). Thus, differentiation has increasingly become a normal feature of European integration, including in the field of research where it has hardly been studied. This highlights the need to better understand the reasons behind and consequences of differentiated integration.

Schimmelfennig et al (2015: 765) distinguish between vertical and horizontal differentiation. While in their view vertical differentiation means that policy areas have been integrated at different speeds and have reached different levels of centralization over time, horizontal differentiation relates to the territorial dimension and refers to the fact that many integrated policies (including research) are neither uniformly nor exclusively valid in the EU member states. Furthermore, horizontal differentiation can be internal, i.e. some member states do not participate in integration, or it can be external, i.e. some non-members participate in selected EU policies (Schimmelfennig et al 2015: 767).

To explain horizontal differentiation, Schimmelfennig et al (2015: 765) propose two main factors - "interdependence" and "politicization", with interdependence acting as a driver of integration, and politicization acting as an obstacle to uniform integration. Interdependence and politicization vary across policy area, country and time (Leruth 2015; Schimmelfennig et al 2015), and internal horizontal differentiation results from high interdependence and high politicization (Schimmelfennig et al 2015). Interdependence focuses on the benefits of cooperation, while the main indicators of politicization are "mass-level salience and contestation of European integration, the mobilization of Eurosceptic public opinion by Eurosceptic parties and opportunities to voice Eurosceptic opinions in national referendums or elections to the European Parliament" (Schimmelfennig et al 2015: 771). Admitting that their comparative categorical measurement of the conditions of interdependence and politicization is not straightforward and is based on plausibility, Schimmelfennig et al (2015: 775) argue that cases of "high interdependence" are characterized by high transnational exchange, significant economies of scale and important international externalities. They characterize cases of "high politicization", with significant autonomy concerns for governments and identity concerns for nation-state citizens.

Do these two factors - interdependence and politicization - help us to understand drivers behind differentiated integration in the case of RIs, namely why some EU non-members are eager to join ERIC initiatives and a number of member states decide not to join? Can high interdependence and high politicization explain differentiated integration initiatives in the case of RIs? The first explanatory variable - high interdependence - is clearly present. As explained 
above, RIs on the European level are characterized by an active international research collaboration which is necessary to mobilize the required scientific, material, political and financial resources. However, while the overall interdependence of research activities is high, there can be some variation in the level of interdependence across specific research fields and countries. It has been argued that intergovernmental research funding schemes should be "flexible enough for the requirements of different knowledge areas and societal challenges" (Edler 2012: 331). Thus, it can be expected that differentiated integration in research policy results from the variation of interdependence across different research fields for different countries.

The second explanatory variable - high politicization - is well known in the history of European research integration. Even if the main indicators of politicization in the differentiated integration literature outlined above (e.g. mass-level salience and contestation of European integration, mobilization of public opinion, opportunities to voice Eurosceptic opinions) are not present in the case of RIs, major initiatives in this field - as outlined above - have been surrounded with political debates about national sovereignty versus common good and related questions of juste retour and political, economic and diplomatic costs and benefits. Hallonsten (2016: 33-4) refers to the concept of "pork barrel politics" to emphasize the importance of political considerations - e.g. benefits of hosting a major facility (namely political "pork") - in the launch and maintenance of Big Science and large-scale RIs. Thus, according to the differentiated integration approach, it can be expected that a country will join a Big Science or RI initiative such as ERIC in a specific research field if it has high scientific interdependence and low politicization in terms of negative public opinion (e.g. Euroscepticism). Clear political benefits (i.e. "pork"), such as the opportunity to host the project, would facilitate participation.

Thus, the differentiated integration approach can provide a useful lens for studying the dynamics of forming and running initiatives such as ERICs and exploring their benefits and shortcomings in the light of research policy and European integration. However, further operationalization and systematic application of this framework for the cases of RIs goes beyond the scope of this chapter and should be considered for future studies.

\section{CHANGES IN EUROPEAN UNION POLICY AFFECTING BIG SCIENCE AND RESEARCH INFRASTRUCTURES}

To study developments in EU research policy affecting Big Science and RIs, this chapter adopts the three-dimensional framework of Big Science - Big Organizations, Big Machines and Big Politics - developed by Hallonsten (2016). While this framework was developed to study changes in a different 
historical context, this chapter adopts it to study ongoing developments along organizational, instrumentation and political dimensions that in this case are EU support for politically motivated large-scale projects and e-infrastructures as well as developing EU policies towards RIs in the context of the ERA. While it is not possible to provide an exhaustive analysis of changes in EU policies, the three above mentioned developments capture a number of important trends affecting Big Science and RIs in Europe.

\subsection{Big Organizations: Politically Motivated Large-Scale Research Projects}

One novel feature of Big Science in Europe is the emergence of politically motivated large-scale research projects. If traditionally the size of science organizations has been mainly related to epistemic features of scientific disciplines and research fields, then in this new type of organization the size of the project is determined by political decisions. Traditionally, EU science funding has supported a large number of relatively small science projects. In EU policy rhetoric, this has been interpreted as fragmentation of funding, and calls have been made for large-scale EU initiatives to compete with other global science super-powers, especially the United States. The Innovation Union Flagship Initiative of the Europe 2020 strategy launched in 2010 highlighted the importance of partnering as a means to address Europe's insufficient and fragmented research and innovation efforts (European Commission 2014a). Such large-scale initiatives in the 7th FP and Horizon 2020 included industry-led public-private partnerships (joint technology initiatives, contractual public-private partnerships), member state-led public-public partnerships (ERA-NET Cofund, Article 185 initiatives, joint programming initiatives), European Innovation Partnerships, Knowledge and Innovation Communities and Future Emerging Technologies (FET) flagships.

This section takes a closer look at the FET Flagships, which in comparison to other large-scale partnerships are envisaged to be science-driven research initiatives that are led by scientific communities in shaping their programs and building up industrial partnership over time (European Commission 2014a). The plan to identify and launch "two or three bold new FET research flagship initiatives which will drive large multidisciplinary research community efforts towards foundational breakthroughs at the frontier of ICT [information and communication technology]" was announced in the communication "Moving the ICT frontiers" (European Commission 2009). This document was published during the times of economic crisis, when EU rhetoric presented increased investments in research and innovation as sources to boost Europe's competitiveness and to facilitate renewed growth (Ulnicane 2016b). 


\section{Table 4.1 Evolution of FET Flagships}

\begin{tabular}{|c|c|}
\hline Year & FET Flagship development \\
\hline 2009 & $\begin{array}{l}\text { Communication "Moving the ICT frontiers" suggests a new funding instrument: FET } \\
\text { Flagships }\end{array}$ \\
\hline 2010 & $\begin{array}{l}\text { Open consultation with the scientific community on initial ideas } \\
\text { Call for FET Flagships published and } 21 \text { proposals received }\end{array}$ \\
\hline 2011 & Selection of six pilot projects after evaluation of initial proposals \\
\hline 2012 & Six pilot projects submit their flagship proposals \\
\hline 2013 & $\begin{array}{l}\text { Two winners announced: Graphene and Human Brain Project } \\
\text { Start of the projects }\end{array}$ \\
\hline 2014 & Staff working document on FET Flagships \\
\hline 2015 & Signature of Framework Partnership Agreements under Horizon 2020 (8th FP) \\
\hline 2017 & Publication of FET Flagships interim evaluation \\
\hline 2018 & Launch of the third FET Flagship Quantum \\
\hline $\begin{array}{l}\text { late } 2018 \text { / } \\
\text { early } 2019\end{array}$ & $\begin{array}{l}\text { During Horizon Europe negotiations (9th FP), plans for future FET Flagships abandoned } \\
\text { Unclear future for six new pilot projects that were selected in } 2018\end{array}$ \\
\hline
\end{tabular}

Source: Own compilation based on European Commission (2013, 2019d); Kupferschmidt (2019).

Building on the well-regarded FET program for high risk research, the European Commission called for a doubling of its investment in transformative foundational research and FET by 2015, and the launch of FET Flagships was part of this agenda (European Commission 2009). While the main focus of FET Flagships is on ICT research, they are interdisciplinary. The FET Flagships "run typically for a period of 10 years and mobilise hundreds of researchers across Europe with an overall support of around EUR 1 billion" (European Commission 2019d). While these initiatives are often known as "one billion projects", actual funding from the EU FP can be less than half of that expecting that the rest has to be attracted from industry, national government and other sources.

After several years of consultations and competitive multistage selection processes, in 2013, the first two FET Flagships - Graphene and the HBP were launched (for the timeline of the development of FET Flagships see Table 4.1). The third flagship Quantum Technology was launched in 2018.

According to the European Commission (2014a),

flagships are visionary, science-driven, large-scale initiatives addressing grand scientific and technological (S\&T) challenges. They are long-term initiatives bringing together excellent research teams across various disciplines having a unifying goal and an ambitious research roadmap on how to achieve it. Flagships aim at transformational impacts on science and technology, delivering a key competitive advantage for European industry and substantial benefits for society. 
Flagships are expected to bring future growth and competitiveness and "establish Europe as a global leader in their domain" (European Commission 2014a). Under the Horizon 2020 Programme, which is organized according to the three priorities of Excellent Science, Industrial Leadership and Societal Challenges (Ulnicane 2015b, 2016a), FET Flagships are funded under the Excellent Science Pillar (European Commission 2019e). However, as the framing of FET Flagship aims in the EU documents suggests they are expected to deliver on multiple objectives of excellence, relevance and innovation.

During the preparations for the next EU FP called Horizon Europe (2021-27), it was decided to abandon the plans for future FET Flagships (Kupferschmidt 2019) despite the fact that six new flagship pilots have been selected and awarded $€ 1$ million each for preparing their proposals (Abbott 2019). The ending of the FET Flagship instrument has been explained by the need to streamline too many different funding instruments and funding approaches (Kupferschmidt 2019).

While the three FET Flagships continue to operate, it is important to analyze what can be learned from this large-scale politically motivated science funding experiment for future organization and funding of research. In cases like this, when the size and length of the project is motivated by the political agenda on competitiveness, the two dimensions of Big Organizations and Big Politics become closely intertwined.

\subsection{Big Machines: Support for e-Infrastructures}

The development of instrumentation of Big Science and RIs are undergoing important changes. In addition to traditional Big Machines such as accelerators and reactors, new types of scientific instrumentation and apparatus are emerging including digital research infrastructures (Olson et al 2008; see also Franssen, ch 7 in this volume). The EU policy is actively promoting these new types of digital infrastructures that it calls "e-Infrastructures" and that "provide digital-based services and tools for data- and computing-intensive research in virtual and collaborative environments" and that the Commission sees as being "key in future development of research infrastructures" (European Commission 2019f). Against the background of discourse of data revolution, the European Commission has launched and funded a number of e-infrastructure initiatives to support European super-computers and the European Open Science cloud.

The need to support these new types of instruments was highlighted already in the ERA initiative that recognized the need for electronic infrastructures such as data repositories and high-speed networks (European Commission 2007) and ICT-based e-infrastructures "that enable increasingly prevalent data-intensive collaborative research by geographically dispersed teams" 
(European Commission 2012). Vision for the European scientific e-infrastructures for 2030 was set out by the High Level Expert Group on Scientific Data (European Commission 2010a) framing it as follows: "Our vision is a scientific e-infrastructure that supports seamless access, use, re-use, and trust of data. In a sense, the physical and technical infrastructure becomes invisible and the data themselves become the infrastructure - a valuable asset, on which science, technology, the economy and society can advance". These new types of instrumentation come with new organizational and political aspects that are not present in the cases of traditional Big Machines. One such question is about the ethical, legal and social aspects of Big Science and RIs which are particularly relevant in the case of data infrastructures of life sciences that rely on patient data (Goisauf et al 2019).

\subsection{Big Politics: ERA and RIs}

If historically RIs in Europe were established as intergovernmental initiatives outside the EU framework, then the main developments towards EU policy on RIs started within the ERA initiative launched in 2000. EU policy towards RIs evolved gradually in parallel to the development of the ERA initiative (see Table 4.2).

As Table 4.2 demonstrates, since the launch of the ERA, the EU policy towards RIs has evolved from a general recognition of the need to define a common approach to very specific actions such as the launch of the legal framework and quantitative targets for the construction of RIs.

The launch of the ERA initiative in 2000 was motivated by concerns about the EU's competitive position vis-à-vis the United States and Japan as well as about the lack of coordination between national and EU research policies (Ulnicane 2015b). To address this, the ERA initiative outlined action lines including more coherence and common approaches to investments and human resources. Among actions, the initial ERA document called for a definition of a European approach to RIs (European Commission 2000). The document stated that already for several years the EU had been operating a program of support for RIs which had provided support for transnational access to facilities, for the development of new instruments and equipment, and for cooperation projects designed to improve the interoperability of installations and the complementarity of their activities. It called for going a step further and developing "a European approach to infrastructures, covering both the creation of new installations, the functioning of existing ones and access to them" (European Commission 2000).

The idea that RIs cannot be dealt with effectively at national level was repeated in an early review of the ERA (European Commission 2002), which reinforced the idea that "research infrastructures top the list of areas where 
Table 4.2 Evolution of EU policy towards Research Infrastructures within the ERA initiative

\begin{tabular}{|c|c|c|}
\hline Year & Developments in ERA initiative & Relevance for RIs \\
\hline 2000 & $\begin{array}{l}\text { Communication "Towards } \\
\text { European Research Area" }\end{array}$ & $\begin{array}{l}\text { Need to define a European approach to research } \\
\text { infrastructures }\end{array}$ \\
\hline 2002 & $\begin{array}{l}\text { Communication "The European } \\
\text { Research Area: Providing a new } \\
\text { momentum" }\end{array}$ & Creation of ESFRI \\
\hline 2007 & $\begin{array}{l}\text { Green Paper "The European } \\
\text { Research Area: New perspectives" }\end{array}$ & $\begin{array}{l}\text { Developing world-class research infrastructures, including } \\
\text { an appropriate legal structure }\end{array}$ \\
\hline 2008 & $\begin{array}{l}\text { Reports from the expert groups set } \\
\text { up following the Green Paper }\end{array}$ & $\begin{array}{l}\text { Report of the ERA Expert Group "Developing } \\
\text { World-Class Research Infrastructures for the European } \\
\text { Research Area" }\end{array}$ \\
\hline 2009 & $\begin{array}{l}\text { Lisbon Treaty comes into force } \\
\text { with objective of achieving } \\
\text { ERA and shared competence for } \\
\text { research }\end{array}$ & Council decision on the ERIC framework \\
\hline 2010 & & $\begin{array}{l}\text { Report of the (second) Expert Group on Research } \\
\text { Infrastructures: "A vision for strengthening world-class } \\
\text { research infrastructures in the ERA" }\end{array}$ \\
\hline 2010 & $\begin{array}{l}\text { Europe } 2020 \text { and Innovation } \\
\text { Union; deadline to complete ERA } \\
\text { by } 2014\end{array}$ & $\begin{array}{l}\text { Innovation Union target: by } 2015 \text {, launch or complete the } \\
\text { construction of } 60 \text { percent of the prioritized RIs identified } \\
\text { by ESFRI }\end{array}$ \\
\hline 2012 & ERA reform agenda & $\begin{array}{l}\text { Effective investment in and use of RIs included in the ERA } \\
\text { priorities }\end{array}$ \\
\hline 2014 & $\begin{array}{l}\text { Launch of ERA monitoring via } \\
\text { regular Progress Reports }\end{array}$ & Monitoring of ESFRI roadmaps and projects \\
\hline 2015 & ERA roadmap 2015-20 & Optimal use of public investments in RIs \\
\hline
\end{tabular}

Source: Own compilation based on Ulnicane (2015b).

a European approach is called for, given the levels of funding and the need for them to be given the means to ensure they are able to provide services on a European scale". The main achievement in the area of RIs reported in this document was the creation of ESFRI in 2002 "to facilitate the emergence of a European policy on the development and use of research infrastructures in Europe, as well as multilateral initiatives in this field" (European Commission 2002).

The ERA Green Paper in 2007, that launched a broader public, stakeholder and expert involvement with the ERA, introduced the discourse of "world-class research infrastructures" (European Commission 2007). One of the six features that the ERA should have, according to the Green Paper, was 
"world-class research infrastructures, integrated, networked and accessible to research teams from across Europe and the world, notably thanks to new generations of electronic communication infrastructures" (European Commission 2007). Steps towards developing world-class infrastructures included building on the ESFRI roadmap (first published in 2006), making the most of all sources of funding, an appropriate legal structure and further developing electronic infrastructures in Europe and the world.

Following up on the Green Paper, the European Commission established seven Expert Groups, one of which it dedicated to RIs. In 2008 it produced the report "Developing world-class Research Infrastructures for the European Research Area (ERA)" which highlighted the role of RIs for Europe's competitiveness in basic and applied research as well as in generating ideas for industrial, societal and political applications. Among concrete steps, the report mentioned the creation of a legal framework for pan-European RIs. This recommendation was implemented in 2009, when the Council of the EU adopted the ERIC legal framework. In 2010, the second expert group released its report with further recommendations for strengthening RIs in the ERA (European Commission 2010b).

Moreover, in 2010 the Lisbon Strategy was replaced by the Europe 2020 strategy for smart, sustainable and inclusive growth. One of the so-called Europe 2020 Flagship Initiatives was the Innovation Union (European Commission 2010c), which set a deadline for completing the ERA in 2014 as well as a number of specific targets. One of these targets prescribed that "by 2015, Member States together with the Commission should have completed or launched the construction of $60 \%$ of the priority European research infrastructures currently identified by the European Strategy Forum on Research Infrastructures (ESFRI)" (European Commission 2010c).

In light of the deadline for completing the ERA in 2014 and other targets set in the Innovation Union Flagship Initiative, in 2012 the European Commission launched the ERA reform agenda (European Commission 2012). A focus on effective investment in and use of research infrastructures was included in one of the ERA priorities of "Optimal transnational co-operation and competition". To facilitate implementation of the ERA priorities, in 2014 an ERA monitoring process was launched with regular ERA Progress Reports which also monitored the progress on RIs. According to the 2018 ERA Progress Report: "As of 2018, over half of the ERA countries had roadmaps in place together with ESFRI research infrastructures, but only a third of them had also identified funding needs. However, more cooperation and synchronization of national procedures (for setting priorities, monitoring and long-term funding) is needed to make the European research infrastructure ecosystem more robust and increase the effectiveness of public investments in this area" (European Commission 2019g). The top priorities of the ERA Roadmap 2015-20 include 
"making optimal use of public investments in Research Infrastructures (RIs) by setting national priorities compatible with the European Strategy Forum on Research Infrastructures (ESFRI) priorities and criteria taking full account of long term sustainability" (Council of the European Union 2015). Among the points for possible future consideration, the roadmap highlights "the need to step up the efforts in the area of the Research Infrastructures, including the e-infrastructures, and UNDERLINES that the use of the European Structural and Investment Funds for these purposes should be encouraged, where appropriate" (Council of the European Union 2015).

To sum up, the EU policy towards RIs was largely developed within the ERA initiative, demonstrating that the EU includes RIs among the core priorities of European integration in science. Over time this policy developed from broad statements about the need for a common European approach, to concrete actions and decisions. Today EU policy for RIs is largely developed within the ESFRI. Currently, the role of the ERA initiative for RIs is largely limited to monitoring, with results published in the ERA Progress Reports. Overall since the controversial deadline to complete the ERA by 2014 (Ulnicane 2015b, $2016 \mathrm{c}$ ), the role of the ERA initiative in EU research policy has diminished. However, in 2020 it is planned to launch a new strategy for ERA. The EU policy discourse about RIs has shifted from previous grand ambitions of "world-class infrastructures" (European Commission 2007, 2008, 2010a, $2010 \mathrm{~b}$ ) to a more pragmatic recent focus on "sustainable research infrastructures" (European Commission 2017a).

\section{EXAMPLE OF CHANGING EUROPEAN UNION POLICY: THE HUMAN BRAIN PROJECT}

To illustrate changes in EU policy towards Big Science and RIs (discussed in Section 4), this section looks at the HBP. It is one of the two initial FET Flagships (see Section 4.1) launched in 2013 to develop an RI for scientific and industrial researchers to study neuroscience, computing and brain-related medicine. After expiration of its current FET Flagship funding in 2023, it is planning to establish itself as an RI initiative called EBRAINS. Preparations for developing a sustainable RI involve a number of diverse activities from preparing services and building user communities to establishing legal entity and ensuring sustainable funding sources.

The HBP is one of the largest science projects ever funded by the EU, bringing together some 500 researchers and engineers from different scientific disciplines including neuroscience, computing and social sciences. They are based in approximately 120 universities, research institutes and hospitals in some 20 countries. While popularly known as a "one billion project", actual 
funding expected from the FPs over ten years is around $€ 400$ million, and the rest of the funding is expected to be acquired from other sources.

\subsection{Big Organization: From FET Flagship to Sustainable Research Infrastructure}

The EU policy discourse explaining the importance of the HBP states that "understanding the human brain is one of the greatest challenges facing 21 st century science. By rising to the challenge, profound insights into what it means to be human can be gained. New treatments for brain diseases may also become possible, and new knowledge may enable revolutionary new computing technologies" (European Commission 2017b).

Ideas for the HBP originate from the Swiss Blue Brain project that aims to reverse-engineer the mammalian brain. At the beginning, the aim of the HBP, championed by its initial leader Henry Markram, was to build a realistic computer model of the brain by 2023. Already in the HBP proposal in 2012, it was mentioned that building and simulating such models will require infrastructure and ICT platforms branded as infrastructure (Human Brain Project 2012). The European Commission's press release presented the HBP as a "facility", stating that it "will create the world's largest experimental facility for developing the most detailed model of the brain, for studying how the human brain works and ultimately to develop personalised treatment of neurological and related diseases" (European Commission 2013).

Interestingly, initial leaders of this highly risky ICT and neuroscience project aiming to simulate the human brain compared the HBP with well-known successful traditional large-scale initiatives and facilities including CERN, Higgs boson, the Human Genome Project, National Aeronautics and Space Administration, space shuttles and telescopes (see e.g. Frackowiak 2014; Honigsbaum 2013). These comparisons can be seen as attempts to make the HBP more acceptable and understandable as well as to signal the level of ambition.

When the highly risky grand vision came under criticism, the aim to turn the HBP into an RI moved to the forefront as a safer objective for the project's continuation. Less than a year after the HBP was launched, an open letter attacking HBP's science and organization gathered more than 800 signatures of neuroscientists (Theil 2015; see also Mahfoud 2020). Additionally, signatories were concerned that the financing of HBP would drain all the EU and national funds on neuroscience research for the duration of the project (European Commission 2017b). Similar concerns that funding of large digital infrastructures would limit resources for other epistemic approaches can be seen also in other scientific disciplines including humanities (see Franssen, ch 7 in this volume). Major scientific and structural reorganization of the 
Table 4.3 Timeline: from the Human Brain Project to EBRAINS research infrastructure

\begin{tabular}{ll}
\hline Year & Developments \\
\hline 2013 & The Human Brain Project was launched following a competitive selection process \\
2014 & Open letter and mediation process; 1st technical project review \\
2015 & Framework Partnership Agreement includes White Paper on Infrastructure \\
2016 & HBP ICT platforms made available to the public \\
2018 & Start of Computational e-Infrastructure FENIX for EU Neuroscience \\
2019 & Establishment of the RI legal entity \\
2023 & FET Flagship funding ends/continuation as EBRAINS RI expected \\
\hline
\end{tabular}

Source: Own compilation partly based on Human Brain Project (2019a).

HBP followed (with a close involvement of the European Commission) and the main aim of computing the brain was changed to building an RI (for the timeline of the HBP, see Table 4.3). Although the main aim of the project was revised in 2014 and 2015, several years later in the popular press and mass media the HBP is still associated with a vision of building a computer model of the human brain (e.g. Marsh 2019; O'Connell 2017).

The mediation process and the first technical project review that followed the open letter led to important changes including one of the project leadership. The new objectives of the HBP were outlined in the Framework Partnership Agreement (Human Brain Project 2015). The six closely related HBP objectives are (1) to create and operate a European scientific research infrastructure for brain research, cognitive neuroscience and other brain-inspired sciences; (2) to gather, organize and disseminate data describing the brain and its disease; (3) to simulate the brain; (4) to build multiscale scaffold theory and models for the brain; (5) to develop brain-inspired computing, data analytics and robotics; and (6) to ensure that the HBP's work is undertaken responsibly and that it benefits society (Human Brain Project 2015).

The Framework Partnership Agreement also included the White Paper "Transforming the Human Brain Project Platforms into a Community-Driven Infrastructure for Brain Research", which also set out a roadmap for RI development. This focused more specifically on what we here could call instrumentation, and what will be discussed below.

\subsection{Big Machines: ICT Research Platforms}

The HBP is building the EBRAINS RI for collecting, analyzing, sharing, integrating and modelling data about the brain. At the core of this RI are six ICT platforms launched in 2016: Neuroinformatics (access to shared brain data), 
Brain Simulation (replication of brain architecture and activity on computers), High Performance Analytics and Computing (providing the required computing and analytics capabilities), Medical Informatics (access to patient data, identification of disease signatures), Neuromorphic Computing (development of brain-inspiring computing) and Neurorobotics (use of robots to test brain simulation) (Human Brain Project 2019b). Thus, platforms provide access to hardware, software, simulation environments and data sets.

The promise is that "the Platforms will enable new kinds of collaborative research to be performed in neuroscience, medicine and computing. The prototype tools, hardware systems and initial data sets are designed to enable faster and more efficient research techniques in, for example, modelling, in silico experimentation, or data analysis" (European Commission 2017b). Additionally, from 2018 to 2023, the five leading European super-computing centers that form the HBP High Performance Analytics and Computing platform have launched the Interactive Computing E-Infrastructure ICEI/FENIX that provides computing and data services for the HBP as well as for external users.

Key challenges for building research infrastructure include attracting diverse user communities (beyond HBP) and ensuring sustainability and coherence of the infrastructure. To engage the user community and develop collaborations, in 2018 the HBP announced a voucher scheme that gives access to HBP platforms and engineers to solve specific scientific problems. According to the vision for the future of the HBP, "the brain research infrastructure will unify the individual components into one cloud-based super-structure, facilitating the exchange of knowledge, data, models, and algorithms within HBP as well as between the HBP and the "outside world"' (Amunts et al 2019).

Thus, a major effort to develop research infrastructure in this case is undertaken within a fixed-term project without guaranteed future funding. This leads to the next topic: the Big Politics of the HBP.

\subsection{Uncertainty of Big Politics}

So far Big Politics has worked for and against the HBP. Initially, its scientific vision of modeling the human brain received major political support at the EU level in terms of being awarded FET Flagship. However, very soon politics backfired when this high-profile project triggered major critique from the scientific community and in response to the open letter the HBP was reorganized.

The international science context has been an important element in the EU's support for the HBP. Already initial EU policy documents on the first two FET Flagships mention that "understanding the human brain is a global challenge" (European Commission 2014a) and refer to other major brain initiatives in the world including the United States, Canada, Japan, China, Korea and Australia. 
In popular press, international focus on neuroscience has also been framed as a "brain race" (see e.g. Honigsbaum 2013). In 2017, the HBP together with other major initiatives launched an International Brain Initiative to advance ethical neuroscience research through international collaboration and knowledge sharing (see also Savage 2019). Here we can see also elements of science diplomacy: EU scientists interact and exchange ideas with scientists in the United States and China despite the fact that this often sensitive research takes place under very different regulatory and ethical regimes that among other issues affect treatment of personal data and animal research.

Building and maintaining a sustainable research infrastructure after the FET Flagship (i.e. after 2023), e.g. by being included in the ESFRI roadmap, requires mobilization of major political support also at the national level. This means that not all initial project partners might continue their participation in the RI as has been experienced by other initiatives such as the European Social Survey discussed above (Duclos Lindstrom and Kropp 2017). The differentiated integration approach (Section 3.2) suggests that countries will join differentiated initiatives when interdependence is high and politicization is low. International interdependence is relatively new in neuroscience and ICT, which traditionally have not been examples of Big Science. However, a more recent trend towards major brain initiatives around the world and international collaboration between them might increase motivation for national governments to collaborate internationally in this field.

Low politicization in this case is a more uncertain issue due to the HBP's history. Moreover, the need to acquire national support for participation in an infrastructure initiative implies that composition of countries in future infrastructure initiatives might differ from the current national composition of the HBP, thus affecting the coherence of the infrastructure that is being built.

\section{SUMMARY AND OPEN QUESTIONS}

Since the year 2000, the EU has launched major policy agendas focusing on increasing its global competitiveness and improving coordination and collaboration among its member states. In response to the financial crisis in 2008-2009, the EU reinforced these policies to stimulate economic growth. Big Science and RIs are part of this broad EU policy agenda.

This chapter described some ongoing changes in EU policy affecting Big Science and RIs and revealing the evolving role of EU policy on the closely interconnected new developments in three dimensions - Big Organizations, Big Machines and Big Politics - in the EU. Political interest to fund large-scale projects increases influence of political factors on Big Organizations. The EU support for e-infrastructures, data repositories and super-computers, facilitated by the rhetoric of data revolution, enables the development of new types of 
instruments and apparatus in parallel to more traditional Big Machines. The Big Politics of the ERA put RIs at the core of European integration in research. The choice to support RIs in a differentiated integration mode, that brings together selected member states and non-members, provides flexibility but also presents challenges for supranational initiatives.

These developments and the example of the HBP draws attention to a number of open questions about ongoing and future changes and transformations. Are political and scientific factors complementary or contradictory in the case of the launch and governance of large-scale research projects? What lessons can be learned about the governance and effectiveness of such projects? What is the evidence from large-scale research projects on their contribution to fulfilling their diverse objectives of achieving excellence, tackling societal challenges, accomplishing industrial collaboration and contributing to international competitiveness? How can new e-infrastructures be made sustainable? What roles do user communities and other stakeholders play in the development and maintenance of e-infrastructures? Are large-scale digital infrastructures promoted at the expense of other epistemic approaches? Is there a trend towards turning fixed-term scientific projects to become sustainable research infrastructures and is today's science system ready for it? Should EU policymakers consider going beyond differentiated integration-type arrangements in this area, and develop a supranational framework for setting up RIs?

\section{NOTE}

This is an open access work distributed under the Creative Commons AttributionNonCommercial-NoDerivatives 3.0 Unported (https://creativecommons.org/ licenses/by-nc-nd/3.0/). Users can redistribute the work for non-commercial purposes, as long as it is passed along unchanged and in whole, as detailed in the License. Edward Elgar Publishing Ltd must be clearly credited as the owner of the original work. Any translation or adaptation of the original content requires the written authorization of Edward Elgar Publishing Ltd.

\section{ACKNOWLEDGMENTS}

This chapter has benefited from feedback on presentations of earlier drafts at the book workshop in Lund, Sweden, 2019 and the General Conferences of the European Consortium for Political Research in 2018 in Hamburg, Germany and in 2019 in Wroclaw, Poland. Useful recommendations from Tara Mahfoud, Christine Aicardi, Bernd Carsten Stahl and the editors of this book are gratefully acknowledged. The research reported in this chapter has received funding from the EU's Horizon 2020 Research and Innovation Programme under Grant Agreements No. 720270 (HBP SGA1), No. 785907 
(HBP SGA2) and No. 945539 (HBP SGA3). The author has been a researcher within the HBP's Ethics and Society team since December 2017.

\section{REFERENCES}

Abbott A (2019) Europe's next €1-billion science projects: Six teams make it to final round. Nature 566: 164-5.

Amunts K, A C Knoll, T Lippert, C M A Pennartz, P Ryvlin, A Destexhe, V K Jirsa, E D'Angelo and J G Bjaalie (2019) The Human Brain Project: Synergy between neuroscience, computing, informatics, and brain-inspired technologies. PLoS Biology 17 (7): e3000344.

Chou M-H and I Ulnicane (2015) New horizons in the Europe of knowledge. Journal of Contemporary European Research 11 (1): 4-15.

Council of the European Union (2015) Draft conclusions on the European Research Area Roadmap 2015-2020, May 19. Available at http://data.consilium.europa.eu/ doc/document/ST-8975-2015-INIT/en/pdf (last accessed August 25, 2019).

Crawford E, T Shinn and S Sorlin (eds) (1993) Denationalizing science: The contexts of international scientific practice. Springer.

Duclos Lindstrom M and K Kropp (2017) Understanding the infrastructure of European Research Infrastructures: The case of the European Social Survey (ESS-ERIC). Science and Public Policy 44 (6): 855-64.

Edler J (2012) Toward variable funding for international science. Science 338 (6105): $331-2$.

Egenhofer C, P M Kaczynski, S Kurpas and L Schaik (2011) The ever-changing Union: An introduction to the history, institutions and decision-making processes of the European Union, 2nd ed. Centre for European Policy Studies.

European Commission (2000) Towards a European Research Area. Communication $\operatorname{COM}(2000) 6$.

European Commission (2002) The European Research Area: Providing new momentum. Communication COM(2002) 565.

European Commission (2007) The European Research Area: New perspectives. Green Paper. $\operatorname{COM}(2007) 161$.

European Commission (2008) Developing world-class research infrastructures for the European Research Area (ERA). Report of the ERA Expert Group.

European Commission (2009) Moving the ICT frontiers: A strategy for research on future and emerging technologies in Europe. Communication COM(2009) 184.

European Commission (2010a) Riding the wave: How Europe can gain from the rising tide of scientific data. Final Report of the High Level Expert Group on Scientific Data.

European Commission (2010b) A vision for strengthening world-class research infrastructures in the ERA. Report from the Expert Group on Research Infrastructures.

European Commission (2010c) Europe 2020 Flagship Initiative Innovation Union. Communication $\operatorname{COM}(2010) 546$.

European Commission (2012) A reinforced European Research Area partnership for excellence and growth. Communication $\operatorname{COM}(2012) 392$.

European Commission (2013) Graphene and the Human Brain Project win largest research excellence award in history. Available at https://ec.europa.eu/digital -single-market/en/news/graphene-and-human-brain-project-win-largest-research -excellence-award-history (last accessed December 6, 2019). 
European Commission (2014a) FET Flagships: A novel partnering approach to address grand scientific challenges and to boost innovation in Europe. Commission Staff Working Document SWD(2014) 283 final.

European Commission (2014b) Report from the Commission to the European Parliament and the Council on the Application of Council Regulation (EC) No 723/2009 of 25 June 2009 on the Community legal framework for a European Research Infrastruicture Consortium (ERIC). Communication COM(2014) 460.

European Commission (2017a) Sustainable European research infrastructures. Commission Staff Working Document SWD(2017) 323.

European Commission (2017b) FET Flagships interim evaluation. Final Report.

European Commission (2019a) European Research Infrastructures. Available at https://ec.europa.eu/info/research-and-innovation/strategy/european-research -infrastructures_en (last accessed February 13, 2019).

European Commission (2019b) European Research Infrastructure Consortium (ERIC). Available at https:/ec.europa.eu/info/research-and-innovation/strategy/european -research-infrastructures/eric_en (last accessed December 6, 2019).

European Commission (2019c) Associated countries. Available at https://ec.europa.eu/ research/participants/data/ref/h2020/grants_manual/hi/3cpart/h2020-hi-list-ac_en .pdf (last accessed December 6, 2019).

European Commission (2019d) FET Flagships. Available at https://ec.europa.eu/ digital-single-market/en/fet-flagships (last accessed February 15, 2019).

European Commission (2019e) Horizon 2020 FET Flagships. Available at https://ec .europa.eu/programmes/horizon2020/en/h2020-section/fet-flagships (last accessed August 26, 2019).

European Commission (2019f) e-Infrastructures. Available at https:/ec.europa.eu/ digital-single-market/en/e-infrastructures (last accessed November 24, 2019).

European Commission (2019g) ERA Progress Report 2018. Communication $\operatorname{COM}(2019) 83$.

Frackowiak R (2014) Defending the grand vision of the Human Brain Project. New Scientist July 16.

Fumasoli T, A Gornitzka and B Leruth (2015) A multi-level approach to differentiated integration: Distributive policy, national heterogeneity and actors in the European Research Area. ARENA Working Paper 2. Available at www.sv.uio.no/ arena/english/research/publications/arena-working-papers/2015/wp2-15.html (last accessed January 10, 2020).

Goisauf M, G Martin, H B Bentzen, I Budin-Ljøsne, L Ursin, A Durnova et al (2019) Data in question: A survey of European biobank professionals on ethical, legal and societal challenges of biobank research. PLOS ONE 14 (9): e0221496.

Hallonsten O (2012) Continuity and change in the politics of European scientific collaboration. Journal of Contemporary European Research 8 (3): 300-19.

Hallonsten O (2014) The politics of European collaboration in Big Science. In M Mayer, M Carpes and R Knoblich (eds) The global politics of science and technology. Vol. 2: Perspectives, cases and methods. Springer, pp 31-46.

Hallonsten O (2015) Unpreparedness and risk in Big Science policy: Sweden and the European Spallation Source. Science and Public Policy 42 (3): 415-26.

Hallonsten O (2016) Big science transformed: Science, politics and organization in Europe and the United States. Palgrave Macmillan.

Hallonsten O (2020) Research Infrastructures in Europe: The hype and the field. European Review 28 (4): 617-35. 
Holzinger K and F Schimmelfennig (2012) Differentiated integration in the European Union: Many concepts, sparse theory, few data. Journal of European Public Policy 19 (2): 292-305.

Honigsbaum M (2013) Human Brain project: Henry Markram plans to spend $€ 1$ bn building a perfect model of the human brain. Guardian October 15.

Human Brain Project (2012) The Human Brain Project. A report to the European Commission.

Human Brain Project (2015) Framework Partnership Agreement.

Human Brain Project (2019a) Human Brain Project grant structure. Available at www.humanbrainproject.eu/en/about/human-brain-project-ec-grants/ (last accessed December 6, 2019).

Human Brain Project (2019b) Short overview of the Human Brain Project. Available at www.humanbrainproject.eu/en/about/overview/ (last accessed December 6, 2019).

Kölliker A (2001) Bringing together or driving apart the union? Towards a theory of differentiated integration. West European Politics 24 (4): 125-51.

Krige J (2002) The birth of EMBO and the difficult road to EMBL. Studies in History and Philosophy of Science Part C: Studies in History and Philosophy of Biological and Biomedical Sciences 33 (3): 547-64.

Krige J (2003) The politics of European scientific collaboration. In J Krige and D Pestre (eds) Companion to science in the twentieth century. Routledge, pp 897-918.

Kupferschmidt K (2019) Europe abandons plans for "flagship" billion-euro research projects. Science May 14.

Langfeldt L, H Godø, $\AA$ Gornitzka and A Kaloudis (2012) Integration modes in EU research: Centrifugality versus coordination of national research policies. Science and Public Policy 39 (1): 88-98.

Lavenex S (2009) Switzerland in the European Research Area: Integration without legislation. Swiss Political Science Review 15 (4): 629-51.

Leruth B (2015) Operationalizing national preferences on Europe and differentiated integration. Journal of European Public Policy 22 (6): 816-35.

Leruth B and C Lord (2015) Differentiated integration in the European Union: A concept, a process, a system or a theory? Journal of European Public Policy 22 (6): 754-63.

Mahfoud T (2020) Visions of unification and integration: Building brains and communities in the European Human Brain Project. New Media and Society.

Marsh H (2019) Can man ever build a mind? Financial Times January 10.

Moskovko M, A Astvaldsson and O Hallonsten (2019) Who is ERIC? The politics and jurisprudence of a governance tool for collaborative Research Infrastructures. Journal of Contemporary European Research 15 (3): 249-68.

Nedeva M (2013) Between the global and the national: Organising European science. Research Policy 42 (1): 220-30.

O'Connell M (2017) To be a machine: Adventures among cyborgs, utopians, hackers, and the futurists solving the modest problem of death. Granta.

Olson G M, A Zimmerman and N Bos (eds) (2008) Scientific collaboration on the internet. MIT Press.

Papon P (2004) European scientific cooperation and Research Infrastructures: Past tendencies and future prospects. Minerva 42 (1): 61-76.

Papon P (2009) Intergovernmental cooperation in the making of European research. In H Delanghe, U Muldur and L Soete (eds) European science and technology policy: Towards integration or fragmentation? Edward Elgar Publishing, pp 24-43. 
Royal Society (2010) New frontiers in science diplomacy: Navigating the changing balance of power. Royal Society.

Savage N (2019) Brain work. Large-scale national research projects hope to reveal the secrets of the human brain. Nature 574: 49-51.

Schimmelfennig F (2016) Good governance and differentiated integration: Graded membership in the European Union. European Journal of Political Research 55 (4): 789-810.

Schimmelfennig F, D Leuffen and B Rittberger (2015) The European Union as a system of differentiated integration: Interdependence, politicization and differentiation. Journal of European Public Policy 22 (6): 764-82.

Theil S (2015) Why the Human Brain Project went wrong - and how to fix it. Scientific American October 1.

Ulnicane I (2015a) Why do international research collaborations last? Virtuous circle of feedback loops, continuity and renewal. Science and Public Policy 42 (4): 433-47.

Ulnicane I (2015b) Broadening aims and building support in science, technology and innovation policy: The case of the European research area. Journal of Contemporary European Research 11 (1): 31-49.

Ulnicane I (2016a) "Grand challenges" concept: A return of the "big ideas" in science, technology and innovation policy? International Journal of Foresight and Innovation Policy 11 (1-3): 5-21.

Ulnicane I (2016b) Research and innovation as sources of renewed growth? EU policy responses to the crisis. Journal of European Integration 38 (3): 327-41.

Ulnicane I (2016c) Research paper on the European Research Area initiative and the free circulation of knowledge. In C Salm and T Zandstra (eds) European Research Area: Cost of non-Europe report. European Parliamentary Research Service, pp $19-50$.

Vermeulen N, J N Parker and B Penders (2010) Big, small or mezzo? EMBO Reports 11 (6): 420-3.

Wagner C S (2008) The new invisibile college: Science for development. Brookings Institutions Press.

Wagner C S, H Park and L Leydesdorff (2015) The continuing growth of global cooperation networks in research: A conundrum for national governments. PLOS ONE 10 (7): e0131816. 